\title{
Protection of marble surfaces by using biodegradable polymers as coating agent
}

\author{
Yılmaz Ocak ${ }^{a}$, Aysun Sofuoglu ${ }^{\mathrm{b}, *}$, Funda Tihminlioglu ${ }^{\mathrm{b}}$, Hasan Böke $^{\mathrm{c}}$ \\ a Environmental Engineering MSc Programme, Izmir Institute of Technology, Urla 35430, Izmir, Turkey \\ ${ }^{\mathrm{b}}$ Department of Chemical Engineering, Izmir Institute of Technology, Urla 35430, Izmir, Turkey

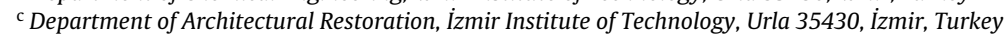

\section{A R T I C L E I N F O}

\section{Article history:}

Received 27 June 2008

Received in revised form 3 April 2009

Accepted 27 July 2009

\section{Keywords:}

Biodegradable polymers

Marble

Air pollution

Protection

Coating

\begin{abstract}
A B S T R A C T
Biodegradable polymers have been replaced over the synthetic polymers in many applications due to their good properties such as reversibility and biodegradability. Therefore they allow new treatment on the surface of the material to be protected and they fulfil the principles generally accepted by the International Conservation Community of Historic Monuments and Buildings.

In this study, the efficiency of four different biodegradable polymers as protective coatings on marble- $\mathrm{SO}_{2}$ reaction was investigated. The polymers used were zein, chitosan, polyhydroxybutyrate (PHB), and poly-L-lactide (PLA). The mineralogical composition, bulk density and porosity of uncoated marble were determined. The water vapor permeability, water absorption by capillary forces, surface wettability, and color alteration of uncoated and coated marbles were measured.

For sulphation reaction, marble slabs were coated with these polymers and then they were exposed at nearly $8 \mathrm{ppm} \mathrm{SO}_{2}$ concentration at $100 \%$ relative humidity conditions together with uncoated ones in a reaction chamber for several days for testing their protection efficiency. The extent of reaction was determined by leaching of gypsum formed on the marble surfaces in deionized water and then determining the sulphate content by ion chromatography.

The protection efficiency of polymer treatments was expressed as comparing the gypsum crust thickness of the coated and uncoated marble plates. The comparison among the polymers showed that the surface hydrophobicity, water capillary absorption and structure of polymer would be important factors affecting the protection efficiency. The use of high molecular weight PLA (HMWPLA) polymer on marble surfaces provided significant protection up to $60 \%$ which was indicated that HMWPLA polymer seems to be promising polymer as protective coating agent in reducing gypsum formation on marble surfaces in the polluted environment.
\end{abstract}

(C) 2009 Elsevier B.V. All rights reserved.

\section{Introduction}

The deterioration of marble monuments and statues has been accelerated by increasing industrialization and heavy urbanization since the last century. Industrialization and heavy urbanization increased the use of fossil fuel that resulted in the increase of sulphur dioxide $\left(\mathrm{SO}_{2}\right)$ concentration in the atmosphere. Sulphur dioxide, the main pollutant affecting the marble structure, reacts with marble composed of calcite crystals $\left(\mathrm{CaCO}_{3}\right)$ and converts it into calcium sulphite hemi-hydrate $\left(\mathrm{CaSO}_{3} \cdot 1 / 2 \mathrm{H}_{2} \mathrm{O}\right)$ [1-3]. Calcium sulphite hemi-hydrate is not a stable product and rapidly oxidized to gypsum $\left(\mathrm{CaSO}_{4} \cdot 2 \mathrm{H}_{2} \mathrm{O}\right)$ by the oxygen in the presence of water $[1,2]$. The reactions take place as follows:

$$
\mathrm{CaCO}_{3}+\mathrm{SO}_{2}+1 / 2 \mathrm{H}_{2} \mathrm{O} \rightarrow \mathrm{CaSO}_{3} \cdot 1 / 2 \mathrm{H}_{2} \mathrm{O}+\mathrm{CO}_{2}
$$

\footnotetext{
* Corresponding author. Tel.: +90 232 7506650; fax: +90 2327506645 .

E-mail address: aysunsofuoglu@iyte.edu.tr (A. Sofuoglu).
}

$\mathrm{CaSO}_{3} \cdot 1 / 2 \mathrm{H}_{2} \mathrm{O}+1 / 2 \mathrm{O}_{2} \rightarrow \mathrm{CaSO}_{4} \cdot 2 \mathrm{H}_{2} \mathrm{O}$

Gypsum is moderately soluble and occupies more volume than $\mathrm{CaCO}_{3}$. As a result, the marble surfaces are eroded in rain-washed areas and disintegrated at sheltered places.

In order to inhibit and/or decrease the $\mathrm{SO}_{2}$-calcite reaction, various precautions have been proposed in the literature. The most common method used to inhibit gypsum formation was coating of stone surfaces by synthetic polymers [3-10]. However, such coatings have been found even more harmful than those uncoated ones due to high absorption of $\mathrm{SO}_{2}$ gas and the entrapment of water vapor by polymers [3].

The other most common method was conversion of the formed gypsum back to calcite form by the use of carbonate solution, but it was not as effective as expected because of the adherence problem of the formed calcite crystals to the original stone surfaces [11]. Furthermore, the possible ways of slowing down the $\mathrm{SO}_{2}$-calcite reaction are producing the less reactive substrate on the marble surface by using some water soluble organic and inorganic compounds 
such as oleate, oxalate and phosphate ions [12-14]. The results of these studies showed that oxalate and oleate anions produced less reactive calcium oxalate and calcium oleate substrate and provided significant protection to marble exposed commonly in sheltered places [13].

Properties of biodegradable polymers fulfil the principles generally accepted by the International Conservation Community since they are reversible, degradable, and allow new treatment of the material to be protected [15]. Although many synthetic polymers were tested and used to protect the marble surfaces from some of the air pollution effects, to our knowledge any biodegradable polymer has not been examined for this purpose.

As previously mentioned, $\mathrm{SO}_{2}$ reacts with calcite in the presence of water $[1,2]$. It is known that some biodegradable polymers have good barrier properties against gas and water vapor. Generally they are used in food packaging industry for preserving food and extending their shelf life. Their biodegradability property puts them in the category of environment friendly packaging part. Hence, by using these types of polymers on the marble surface, it may slow down the gypsum formation. In this study, two different groups of biodegradable polymers were used and tested as a coating agent for preventing gypsum formation on marble surfaces in laboratory conditions. First group polymers known as good gas barrier polymers are zein and chitosan. Zein is a thermoplastic protein with a hydrophobic nature, which is related to its high content of non-polar amino acids. Corn zein protein has been used as a good renewable and biodegradable material for package film forming, coatings, and plastics applications [16]. It has excellent film forming properties and has higher strength and lower gas permeability than other biopolymer films. Chitosan is the second most abundant polymer available in nature which is an edible and biodegradable polymer derived from chitin found in the major structural component of the exoskeleton of invertebrates (crab shrimps, krill, etc.) and of arthropods (insects, crustaceans, and some fungi). Some desirable properties of chitosan are that it has good film forming property without the addition of any additives, shows good oxygen and carbon dioxide permeability, as well as excellent mechanical properties and it has been widely used as an edible coating. Furthermore, chitosan may also be used as coatings on other packaging films to improve gas barrier properties $[17,18]$. However, one disadvantage of chitosan is its high sensitivity to moisture.

Second group polymers, having relatively good water barrier property, are polyhydroxybutyrate (PHB), poly-L-lactide (PLA). PHB is a typical highly crystalline thermoplastic. It is a polyhydroxyalkanoate polymer belonging to the polyesters class. PHB has also high melting point $\left(175-180^{\circ} \mathrm{C}\right)$, water insoluble biodegradable polymer similar to polypropylene (PP) properties. It has a good water vapor barrier property about threefold lower than that of PP. All these properties are notable for water vapor barrier applications [19]. PLA is a biodegradable, thermoplastic, aliphatic polyester derived from renewable resources, such as corn starch or sugarcanes. The properties of PLA are determined by the molecular architecture and the molecular weight [20]. In addition, the degradation behaviour strongly depends on the crystallinity of PLA [20]. The glass transition temperature is in the range of $50-80^{\circ} \mathrm{C}$ while the melting temperature is in the range of $130-180^{\circ} \mathrm{C}$.

In this study, the protection efficiency of some biodegradable polymers on marble- $\mathrm{SO}_{2}$ reaction was investigated. The water vapor permeability, water absorption by capillary forces, surface wettability, and color alteration of uncoated and coated marbles were measured. For sulphation reaction, the extent of reaction was determined by leaching of gypsum formed on the marble surfaces in deionized water and then determining the sulphate content by ion chromatography.

\section{Materials, methods and calculations}

\subsection{Preparation and coating of marble samples}

In this study, Marmara marble was chosen to investigate the protection performances of the biodegradable polymers on marble- $\mathrm{SO}_{2}$ reaction. For the marble- $\mathrm{SO}_{2}$ reaction part, before coating the marble surfaces with biodegradable polymers, firstly rectangular plates (nearly $2.8 \mathrm{~cm} \times 1.6 \mathrm{~cm} \times 0.6 \mathrm{~cm}$ ) were cut from a large block of Marmara marble and polished with 400-grit silicon carbide powder. The samples were then cleaned in ultrasonic bath with distilled water, and dried at $105^{\circ} \mathrm{C}$ and cooled in a dessicator. The four different types of biodegradable polymers that are zein, chitosan, PHB and PLA (high molecular weight and low molecular weight (HMWPLA, LMWPLA)) were tested as coating materials on marble surfaces.

Zein (Sigma-Aldrich) solution was prepared at concentration of $15 \%(\mathrm{w} / \mathrm{v})$ in an aqueous ethanol solution with the addition of glycerol (Sigma). Glycerol was used as a plasticizer to prevent the brittleness of zein polymer. Chitosan (Aldrich) solution was prepared at $2 \%(\mathrm{w} / \mathrm{v})$ concentration by using acetic acid and water mixture. Similarly, PHB (Fluka), LMWPLA (Purac) and HMWPLA (Boehringer) were prepared at concentration of $5 \%(\mathrm{w} / \mathrm{v})$ using chloroform as solvent. The marble plates were then coated with each of these polymer solutions by dip-coating apparatus (Nima dipper) at room temperature with a $100 \mathrm{~mm} / \mathrm{min}$ retraction rate and allowed to dry at $40^{\circ} \mathrm{C}$ in an oven for several hours. Polymer film thickness of the coated marbles was determined by Scanning Electron Microscopy (SEM). The amount of polymer on the coated surfaces ranged between 4 and $5 \mathrm{~g} / \mathrm{m}^{2}$ for the all polymers according to average thickness measured by SEM.

\subsection{Identification of basic physical properties of uncoated and coated marbles}

Mineralogical composition, bulk density and porosity of uncoated marble have been investigated, while water vapor permeability, water absorption by capillary, surface wettability, and color change were also conducted for uncoated and coated samples.

Mineralogical composition of the marble was identified by using a Philips X-Pert X-Ray diffraction (XRD). Bulk density and porosity of marble plates were determined by measuring dry, water saturated under vacuum and hydrostatic weights [21].

The water vapor permeability of uncoated and coated marble experiments were conducted by using a circularly cut (average diameter: 38.5 ; average thickness: $1.5 \mathrm{~mm}$ ) prepared marble. Each of the marble plates replaced in the partially water filled $(1 / 2)$ cylindrical PVC containers. The plates were fixed in these containers in triplicates. Then, their lids were closed and put in the oven at a temperature of $40^{\circ} \mathrm{C}$, and relative humidity around $50 \%$. The containers were weighed every $24 \mathrm{~h}$. When the vapor flow through the samples was less than $5 \%$, the experiments were conducted for 5 more days. During this time, the measurements were repeated and recorded every $24 \mathrm{~h}$. The differences were used to calculate the water vapor fluxes for uncoated and coated plates [21].

Capillary water absorption of uncoated and biopolymer coated plates were measured by gravimetric sorption technique. Uncoated and biopolymer coated marble plates were weighed when they were dry. Then, they were placed on the $1 \mathrm{~cm}$ of filter pad which was immersed in distilled water. $1 \mathrm{~h}$ later, they were weighed again and the results were used to calculate the amount of water absorbed by capillary forces [7].

In order to see the surface hydrophobicity/hydrophilicity of the marble surfaces before and after coating, the static contact angle of the uncoated and coated marble plates were measured with goniometer (Kruss G10). A drop of water was injected from the 
syringe on the material which was replaced on the platform. The angle between the baseline of the drop and the tangent at the drop boundary was measured which gives contact angle of the surface. The samples' contact angles were the average of six measurements.

The color change of polymer coated marbles was also assessed using a colorimeter (Avantes). Uncoated marble, having no biopolymer coating was used as a background for color measurements of the coated marbles. In this system (Hunter system), color is represented as a position in a three-dimensional sphere where the vertical axis $L$ indicates the lightness (ranging from black to white), and the horizontal axes, indicated by $a$ and $b$, are the chromatic coordinates (ranging from $a$ : greenness to redness and $b$ : blueness to yellowness). Hunter $L, a$, and $b$ values were averaged from three readings across for each coating replicate. The total color difference $(\Delta E)$ can be calculated by the following equation:

$\Delta E=\sqrt{(\Delta L)^{2}+(\Delta a)^{2}+(\Delta b)^{2}}$

The results were expressed as $\Delta E$ values, with the substrate marble having no biopolymer coatings as used reference. For each sample, at least three measurements on different positions of surface were made.

\subsection{Experimental setup}

The coated and uncoated (test) marble plates were exposed in a dynamic $8 \mathrm{ppm} \mathrm{SO}_{2}$-enriched atmosphere at room temperature and at $100 \%$ relative humidity in a reactor which was a modified $10 \mathrm{~L}$ dessicator [13]. The samples were placed in the dessicator only after the water had been equilibrated with the supplied concentration of gas. To keep a constant concentration of $\mathrm{SO}_{2}$ in the reactor, not more than four samples were exposed at one time.

The samples were exposed to the $\mathrm{SO}_{2}$ atmosphere as a function of time. The exposure time of coated marble samples changed depending on the degradation degree of the polymer used. Due to rapid degradation of zein and chitosan polymers, the exposure time for them was 35 days. The exposure time to $\mathrm{SO}_{2}$ for PHB, LMWPLA and HMWPLA coated marbles were extended to up to 85 days due to the lower degradation of these polymers compared to chitosan and zein.

\subsection{Experimental methods}

The degree of protection efficiency was determined by comparing the amount of gypsum formed on coated and uncoated marble samples. Gypsum was found by leaching the exposed marble samples in deionized water and then determining the sulphate ions concentration by ion chromatography (Dionex-GP50-2). $\mathrm{SO}_{2}$-marble reaction yields gypsum and calcium sulphide hemihydrate as products. To convert the calcium sulphide hemi-hydrate to gypsum, hydrogen peroxide $\left(\mathrm{H}_{2} \mathrm{O}_{2}\right)$ was added in deionized water [13].

The degradation of polymers and the formation of gypsum crystals on the marble plates were followed by using Scanning Electron Microscope (SEM-Philips XL-30-SFEG).

\subsection{Determination of the thickness of gypsum crust on marble surface}

The protection efficiency of polymers was determined by comparing the amount of gypsum formed on polymer coated and uncoated marble surfaces after each period of $\mathrm{SO}_{2}$ exposure. The amount of gypsum was expressed as crust thickness on the marble plates. The following equations used for the conversion of formed gypsum mass to the thickness of gypsum crust on marble surface

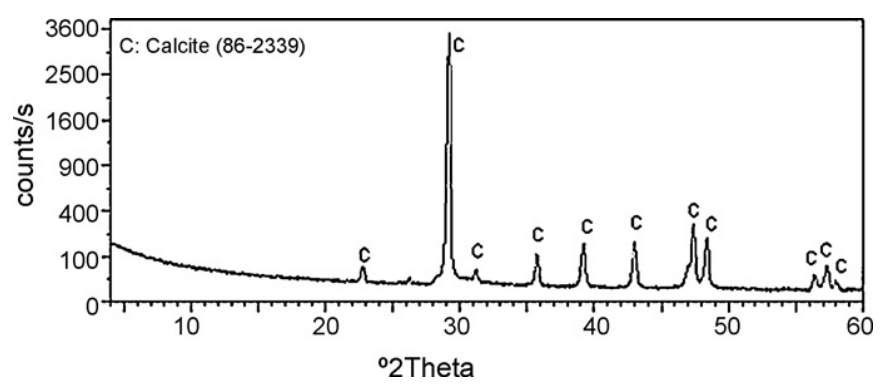

Fig. 1. XRD pattern of Marmara marble.

$[3,13]$. The equations are

$W_{p}=\frac{M_{p}}{M_{A}} W_{A}$

$\delta_{p}=\frac{W_{p}}{A \rho_{c}} \frac{M_{p} \rho_{c}}{M_{c} \rho_{p}}$

where $M_{p}, M_{A}$ and $M_{c}$ are the molecular weights of gypsum, sulphate ion and calcite, respectively. $W_{A}$ and $W_{p}$ are the weights of sulphate and gypsum, respectively. $\delta_{p}$ is the crust thickness $(\mathrm{cm})$ while $\rho_{c}$ and $\rho_{p}$ refer the density of calcite $\left(2.71 \mathrm{~g} \mathrm{~cm}^{-3}\right)$ and gyp$\operatorname{sum}\left(2.32 \mathrm{~g} \mathrm{~cm}^{-3}\right)$ and $A$ is the surface area of the marble plate.

\section{Results and discussion}

\subsection{Basic mineralogical and physical properties of uncoated and coated marble}

Marmara marble has been widely used as building stones at historic monuments and statues in the Marmara and Aegean regions over centuries in Turkey. Mineralogical analysis conducted by XRD showed that it is mainly composed of calcite minerals (Fig. 1). Marmara marble has a moderate density and low porosity values. Its density and porosity values are found as nearly $2.7 \mathrm{~g} / \mathrm{cm}^{3}$ and $0.2 \%$ by volume, respectively.

The water vapor permeability of uncoated and coated marbles was determined as nearly $0.0045 \mathrm{~g} / \mathrm{cm}^{2}$ day. There was no significant difference among coated and uncoated surfaces. It is suggested that the treatment of marble surface should not change the water vapor transmission rate due to not affecting the proper vapor regime inside the stone [22].

Besides the water vapor permeability, it is important to know the contact angle of the uncoated and coated surfaces. The contact angle between a liquid drop and the solid surface is a measure of the angle formed by solid-liquid interface and the liquid-vapor interface. Existence of a large contact angle between the surface of a drop and the surface of the coating material shows that there is lower attraction between the surfaces while a lower contact angle defines the strong attraction between liquid and solid surface and supporting the better adherence to each other [23].

The contact angle measurements of the HMWPLA, LMWPLA, PHB biopolymers coated surfaces were ordered $99^{\circ}, 93^{\circ}, 86^{\circ}$ showing the increase in the hydrophobicity of the marble surface after coating since the surface was polished with 400 -grit silicon carbide powder the contact angle of uncoated marble was $82^{\circ}$. However, for zein and chitosan coated surfaces the contact angle values were reduced to $49^{\circ}$ and $52^{\circ}$ in respect with uncoated surfaces. The effect of hydrophobicity decrease showed itself on the zein and chitosan coated surfaces as poor protection efficiency. The minimum acceptable contact angle is $90^{\circ}$ for stone protection [24]. Based on this criteria, PLA polymers should give better performance in stone protection. 


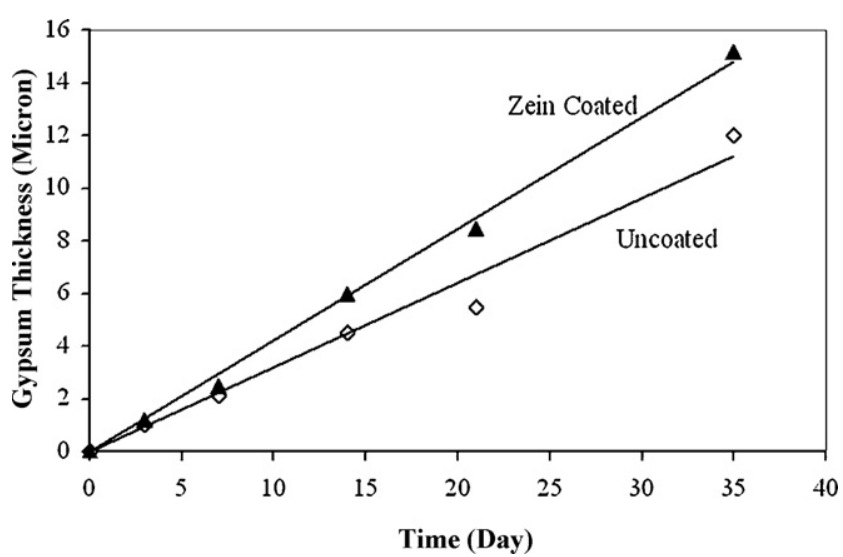

Fig. 2. The thickness of gypsum crust on marble plates with and without zein polymer.

The capillary water absorption measurements were supported by the contact angle results. With respect to uncoated marble, the reduction of the water capillary absorption was ranged $64-81 \%$ for HWMPLA, LMWPLA, and PHB. On the other hand, the enhancement of water capillary absorption was observed for chitosan (200\% more than uncoated), and zein (27\% more than uncoated) polymers.

In general, the coating material should not have any impact on the optical appearance of the marble. In our study, no significant alteration was observed on the color between uncoated and coated marble surfaces. The $\Delta E$ values for the polymers coated surfaces that showed good protection were $3.47,0.36,0.38$ for PHB, LMWPLA, HMWPLA, respectively. It is generally known that $\Delta E=2-3$ refers that the color alteration cannot be detected by naked human eyes [25].

\subsection{Effects of zein and chitosan polymers on $\mathrm{SO}_{2}-$ marble reaction}

The thickness of gypsum crust formed on marble surface was calculated and plotted as a function of time for uncoated, zein, and chitosan coated marble surfaces (Figs. 2 and 3). Higher amount of gypsum formation were observed on zein and chitosan coated samples than that of uncoated ones through $\mathrm{SO}_{2}$ exposure. Even though these polymers are known with a good gas barrier property, this unexpected result can be explained by plasticizing or swelling effects of the water present on the zein, and chitosan surfaces that may increase their gas and water vapor permeability

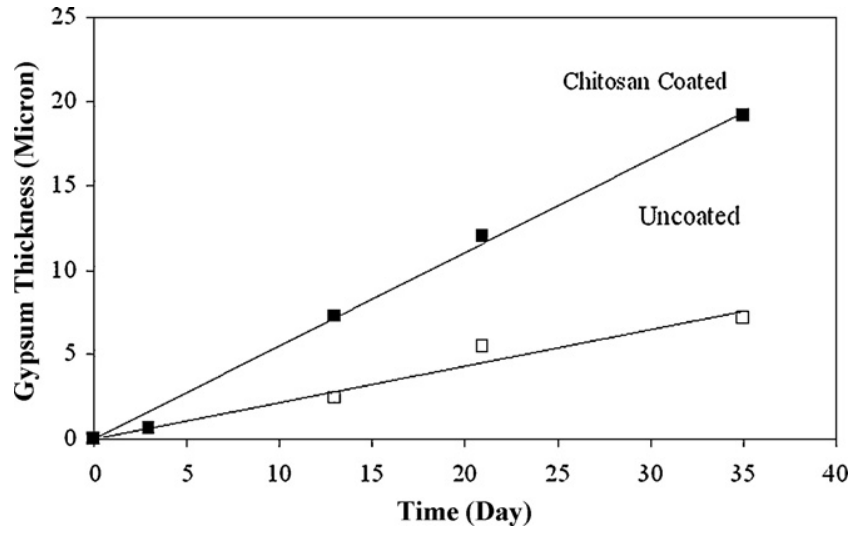

Fig. 3. The thickness of gypsum crust on marble plates with and without chitosan polymer.

[26-28]. The poor protection efficiency of these polymers was also supported with the contact angle measurements. The results showed that when marble coated with these polymers, the surface became even more hydrophilic compared to the uncoated marble. Moreover, the capillary water absorption results showed that the surfaces absorbed water higher than uncoated marble surfaces.

The degradation of polymers and the growth of gypsum crystals on marble surfaces were followed by using Scanning Electron Microscope (SEM) after each period of $\mathrm{SO}_{2}$ exposure. Fig. 4 shows the unexposed and exposed marble surfaces at the end of 35 days. SEM images indicated that uncoated marble was composed of mainly fine calcite crystals (Fig. 4a). At the end of 35 days $\mathrm{SO}_{2}$ exposure, calcite crystals are transformed into long prismatic gypsum crystals (Fig. 4b). Formation of gypsum can be defined by successive stages of gas-liquid-solid interfacial reactions developed on marble surfaces with calcite crystals and $\mathrm{SO}_{2}$ gas $[1,2]$.

Figs. 5a and 6a illustrate the surface morphology of zein and chitosan coated marble surfaces, respectively. As seen in SEM pictures, polymers were uniformly covered on the marble surfaces. The polymer coatings are nearly 3-4 $\mu \mathrm{m}$ ranges in thickness. After each $\mathrm{SO}_{2}$ exposure period, gradually increasing micro-holes and cracks were observed on polymer surfaces with the extended time of exposure. During these periods, gypsum crystals were grown behind the polymers and crystallized on the surface (Figs. $5 \mathrm{~b}$ and $6 \mathrm{~b}$ ). Taken into
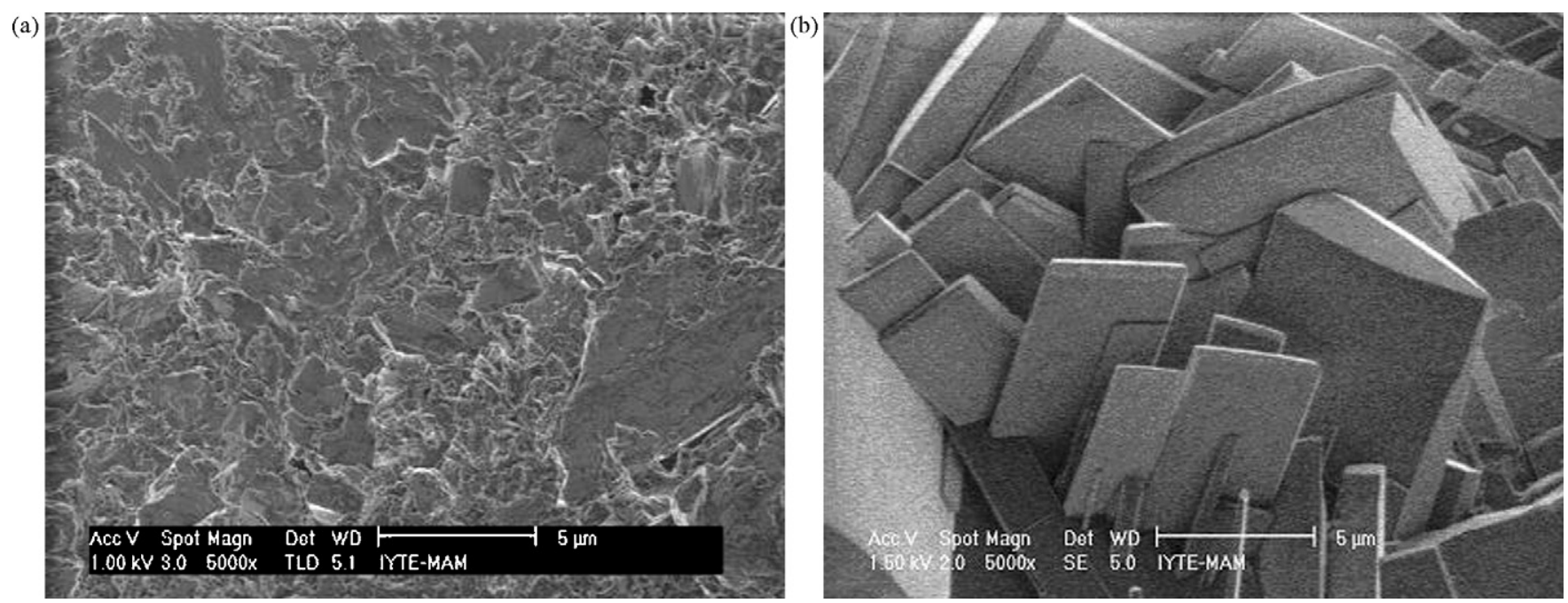

Fig. 4. SEM view of fine calcite crystals of unexposed marble (a) and gypsum crystals formed after 35 days $\mathrm{SO}_{2}$ exposure on marble surface (b). 
(a)

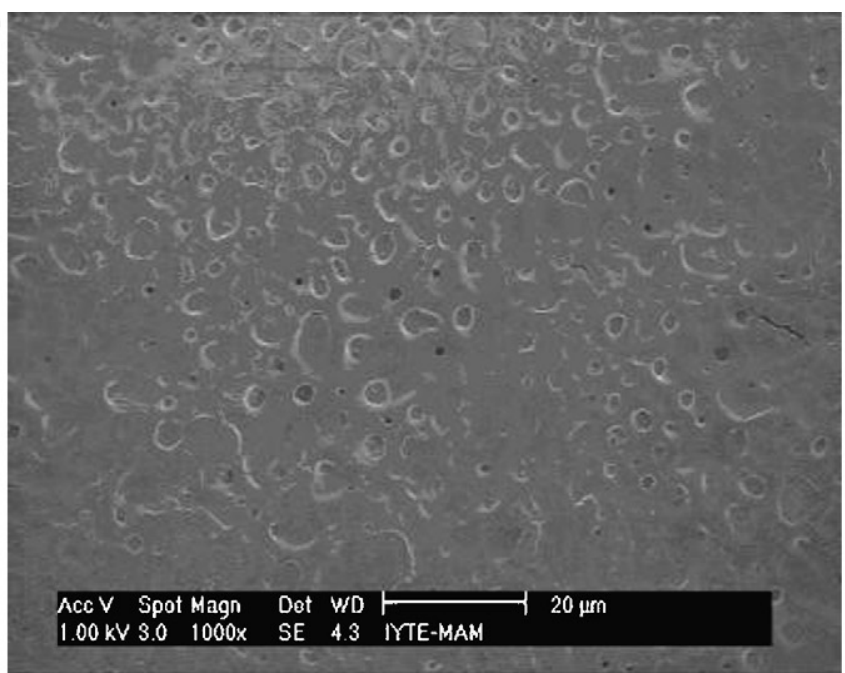

(b)

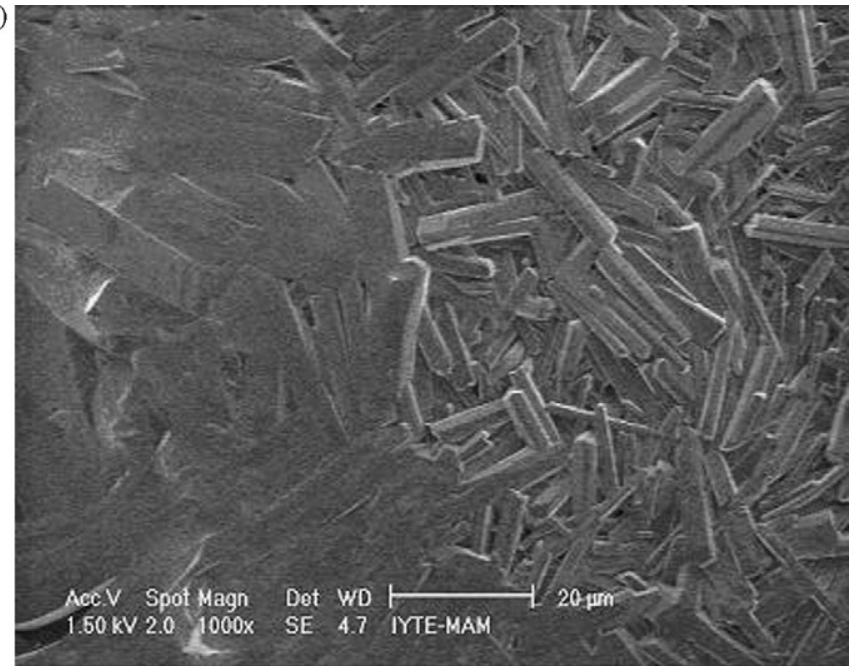

Fig. 5. SEM view of unexposed zein coated marble surfaces (a) and gypsum crystals formed on zein coated marble surfaces after 35 days $\mathrm{SO}_{2}$ exposure (b).

(a)

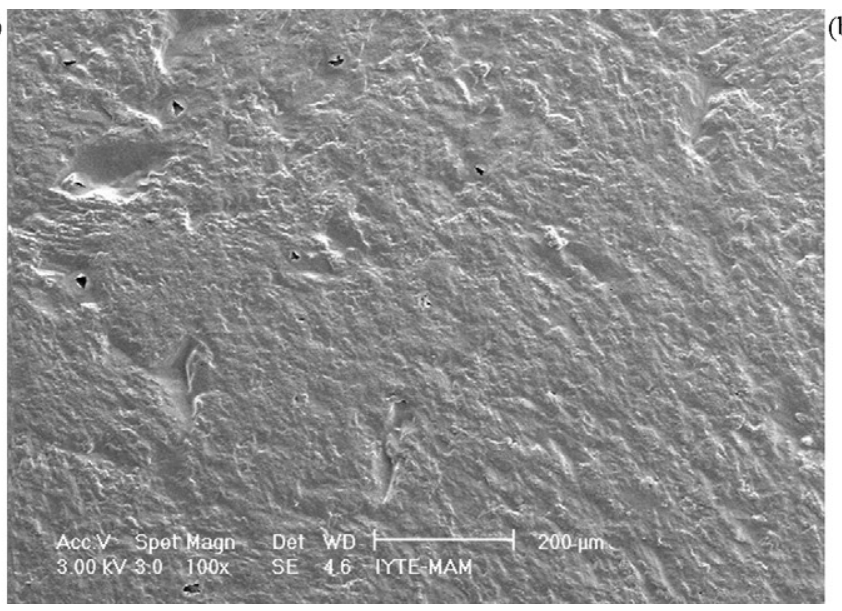

b)

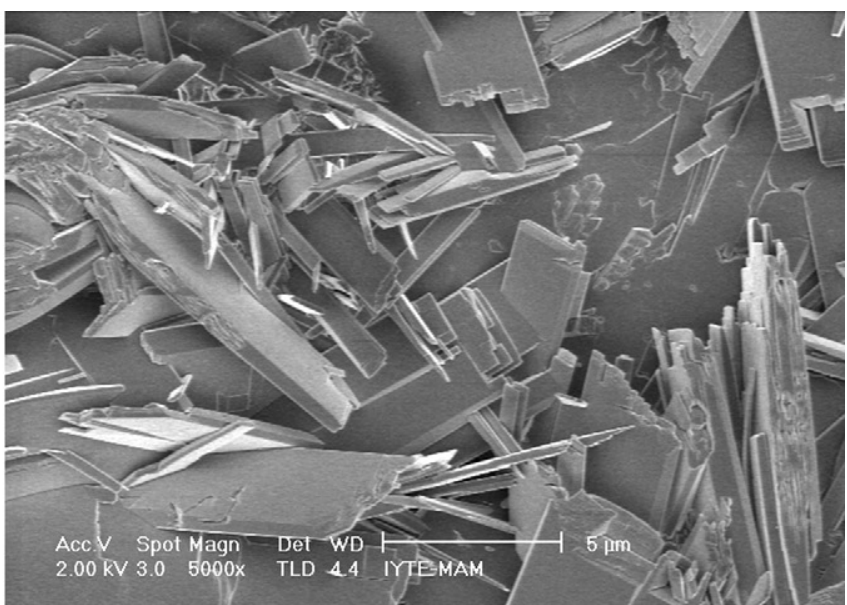

Fig. 6. SEM view of unexposed chitosan coated marble surfaces (a) and gypsum crystals formed on chitosan coated surfaces after 35 days $\mathrm{SO}_{2}$ exposure (b).

account the rapid degradation of polymer films and high amount of gypsum formation on coated marble surfaces, it can be claimed that the use of zein and chitosan as coating material was not effective in inhibiting the marble- $\mathrm{SO}_{2}$ reaction.

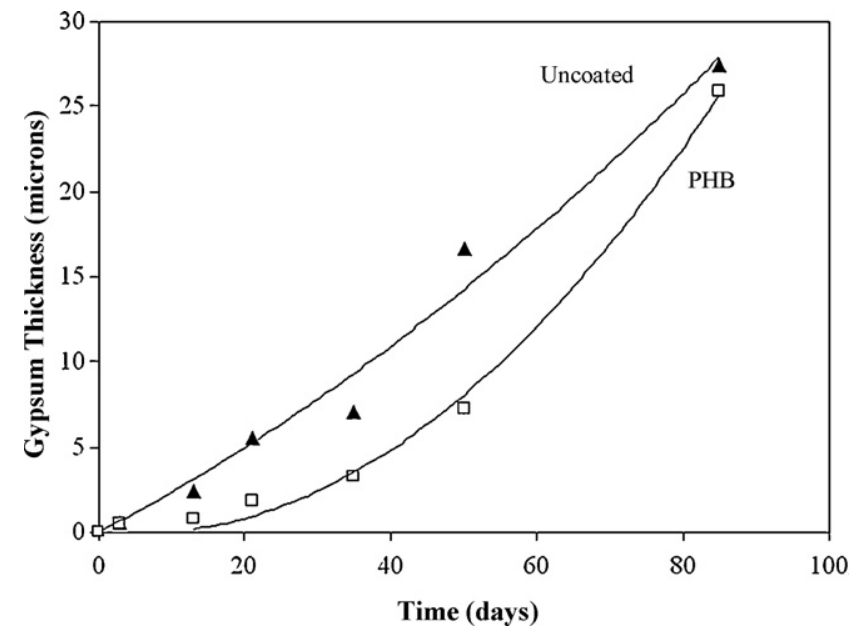

Fig. 7. The thickness of gypsum crust on marble plates with and without PHB.

\subsection{Effects of polyhydroxybutyrate (PHB) and poly-L-lactide (PLA) on $\mathrm{SO}_{2}$-marble reaction}

The thickness of gypsum crust formations on PHB coated and uncoated marble surface showed that PHB polymer reduced the gypsum formation until 50th day of exposure period and then lost

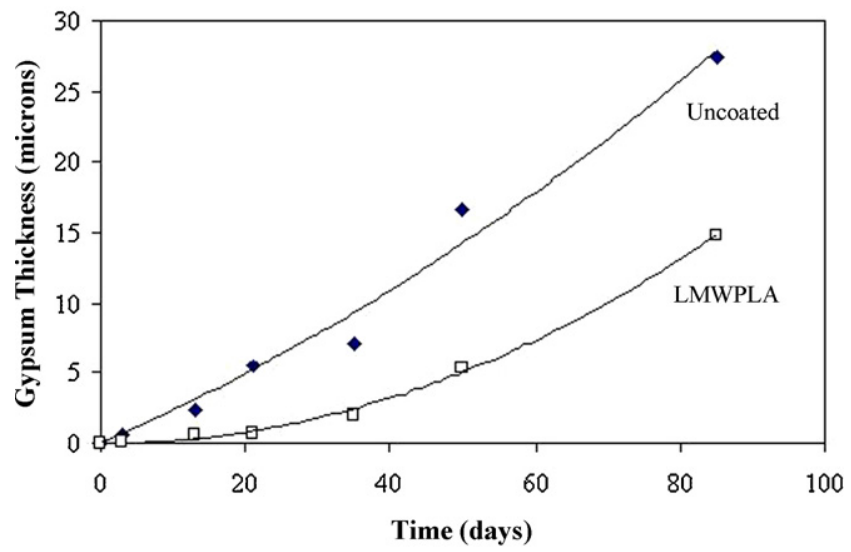

Fig. 8. The thickness of gypsum crust on marble plates with and without LMWPLA. 


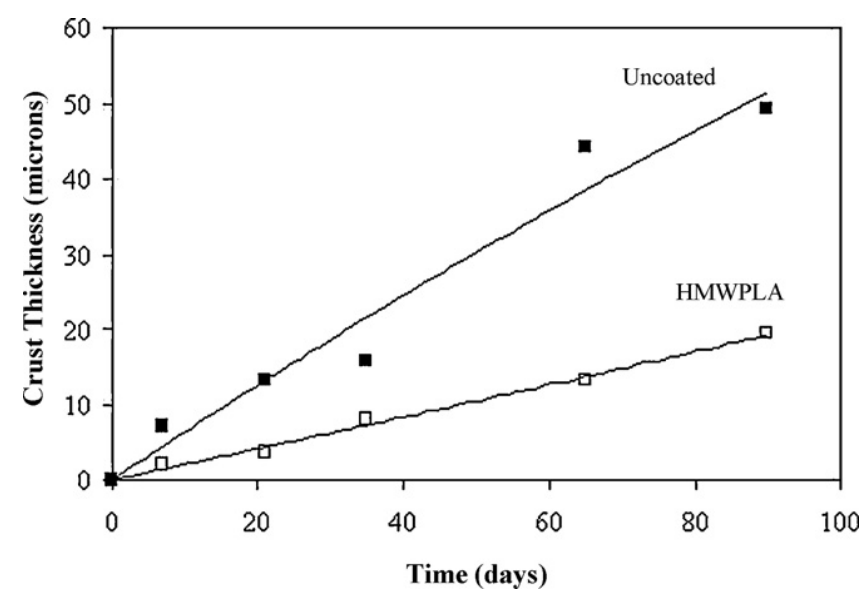

Fig. 9. The thickness of gypsum crust on marble plates with and without HMWPLA.

its protection (Fig. 7). On the other hand, LMWPLA and HMWPLA reduced gypsum formation on marble surfaces over an 85th day of exposure period (Figs. 8 and 9). These results showed that PHB and PLA polymers behaved as protective films on marble surfaces against the effects of $\mathrm{SO}_{2}$ gas. Better performance was obtained from HMWPLA due to its lower degradation rate than that of PHB and LMWPLA. In addition to lower degradation rate, the highest contact angle was also observed indicating that the lower vapor-solid interaction. The capillary water absorption values for these polymers were proving the reduction of water as well.

During the period of 85 days exposure, the gypsum crystals were observed on the degraded part of the surface of the both LMWPLA and PHB coated marble surfaces (Figs. 10 and 11). However, gypsum crystals were rarely observed on the degraded part of HMWPLA coated marble (Figs. 12 and 13).

The protection performance of biodegradable polymer (\%P) can be established by comparing the gypsum crust thickness of coated marbles $\left(C \delta_{p}\right)$ with uncoated ones $\left(U \delta_{p}\right)$. Gypsum crust thicknesses can be accepted as $100 \%$ for uncoated marble and all calculations were done by this assumption.

$\% \mathrm{PP}=100-\frac{U \delta_{p} \cdot 100}{C \delta_{p}}$

The protection performances of polymers are shown in Fig. 14. As it is seen in this figure, HMWPLA polymer was the excellent coating agent for reducing the gypsum formation. The protection (a)

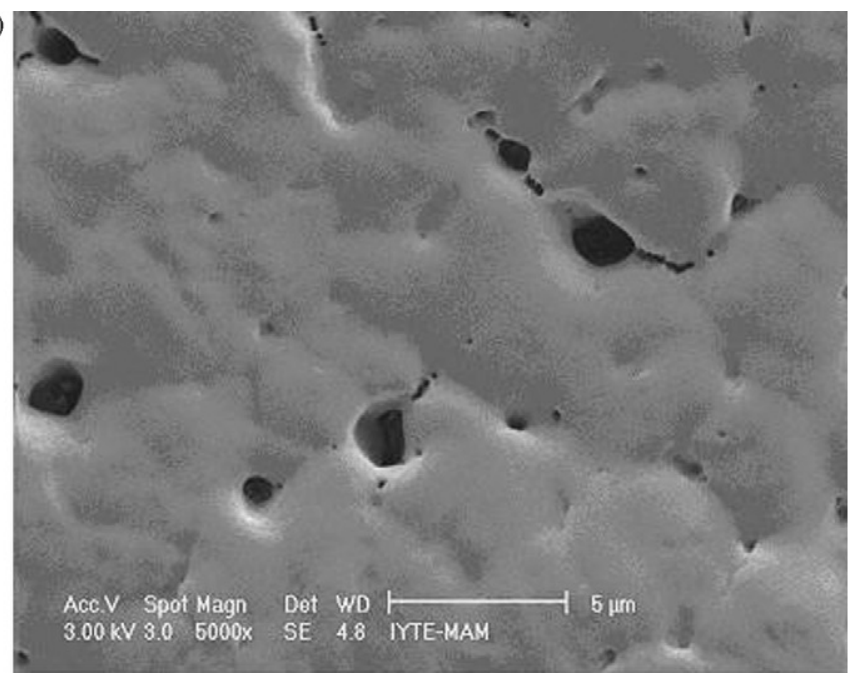

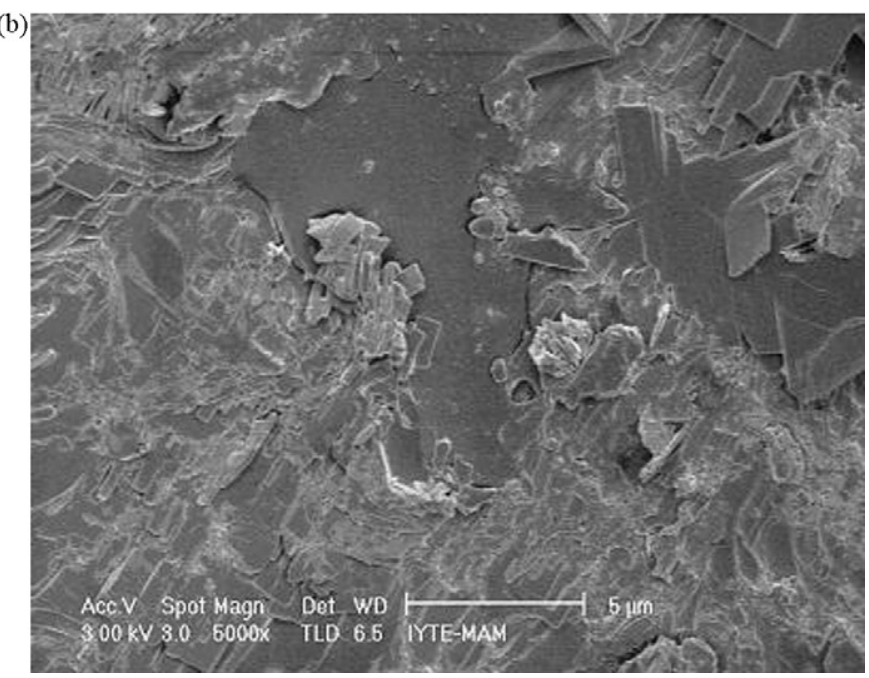

Fig. 10. SEM view of unexposed PHB coated marble surface (a) and gypsum crystals formed on PHB coated surfaces after 85 days $\mathrm{SO}_{2}$ exposure (b).

(a)

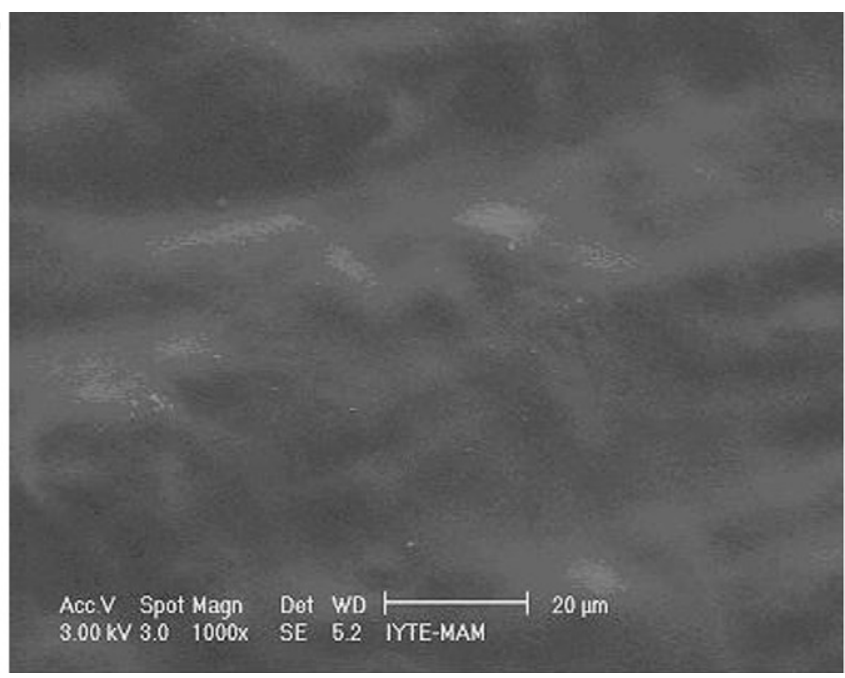

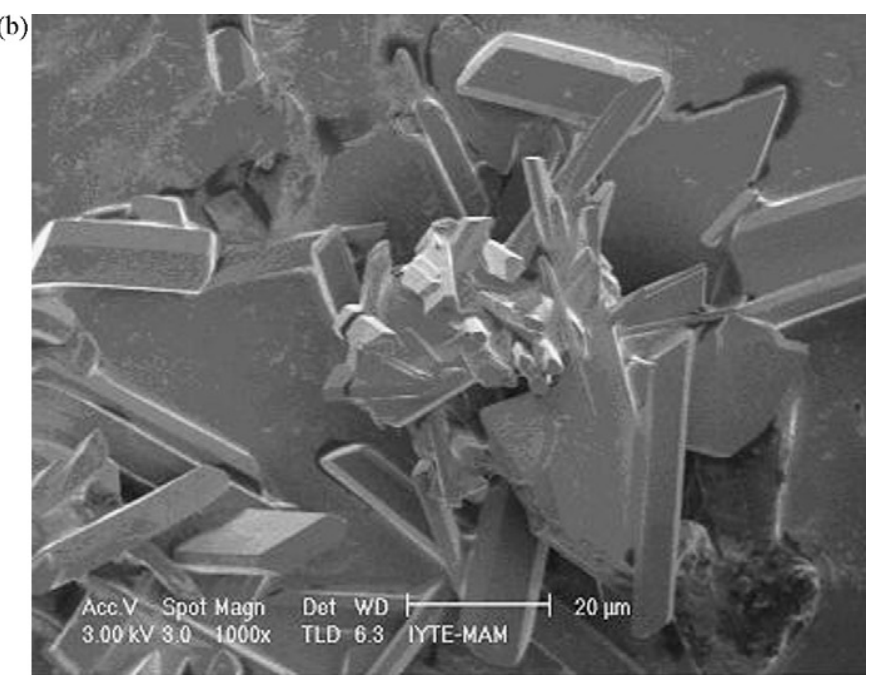

Fig. 11. SEM view of unexposed LMWPLA coated marble surface (a) and gypsum crystals formed on LMWPLA coated surfaces after 85 days SO ${ }_{2}$ exposure (b). 


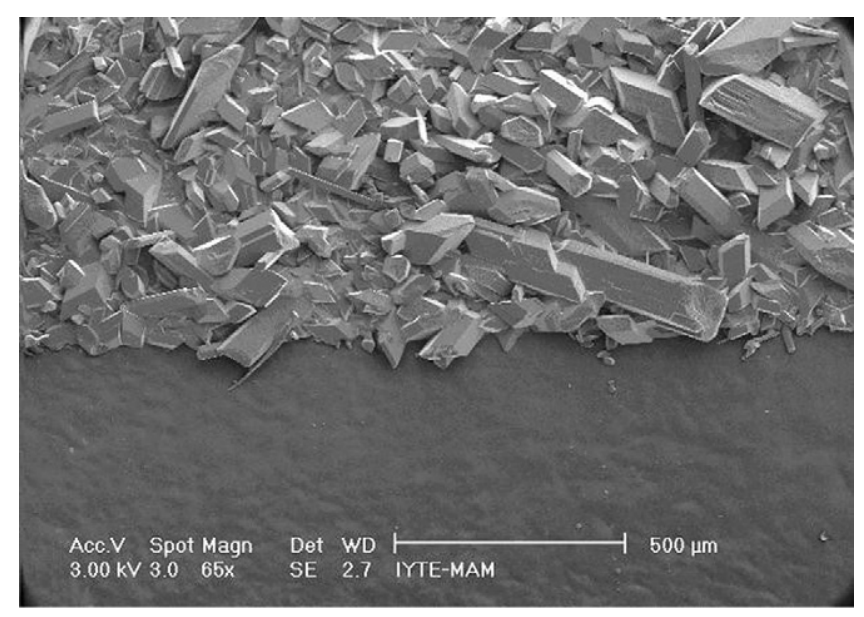

Fig. 12. General SEM view of uncoated and HMWPLA coated marble surfaces after 85 days $\mathrm{SO}_{2}$ exposure.

differences between HMWPLA and LMWPLA polymers could be resulted in differences of molecular weight and crystallinity which directly affect on the free volume and the glass temperature $\left(T_{\mathrm{g}}\right)$ of the polymer. Since HMWPLA had less free volume and

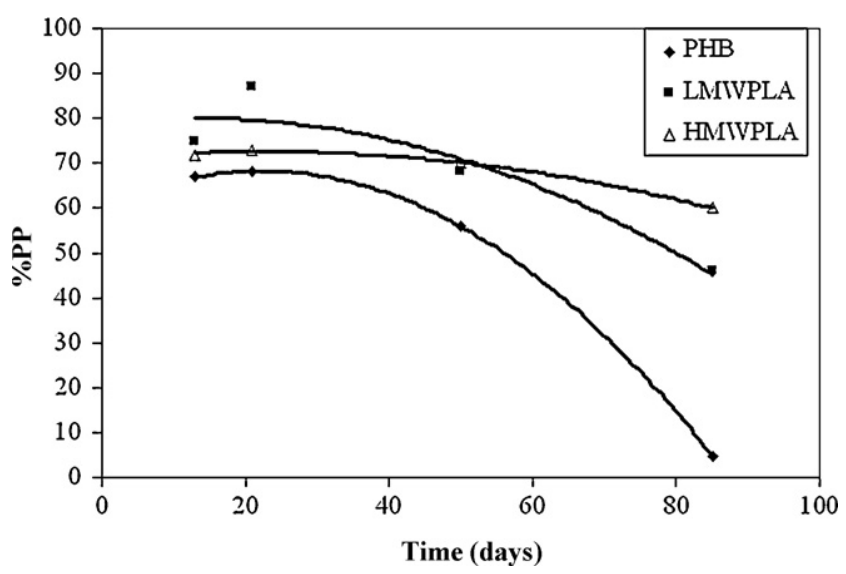

Fig. 14. \% protection performance of the PHB, HMWLPLA and HMWHPLA polymers on marble surfaces.

high glass temperature which caused to slower diffusion of water vapor and $\mathrm{SO}_{2}$ gas. It could be also noted that the increase in MW of coating agent could delay the degradation of the polymer. (a)

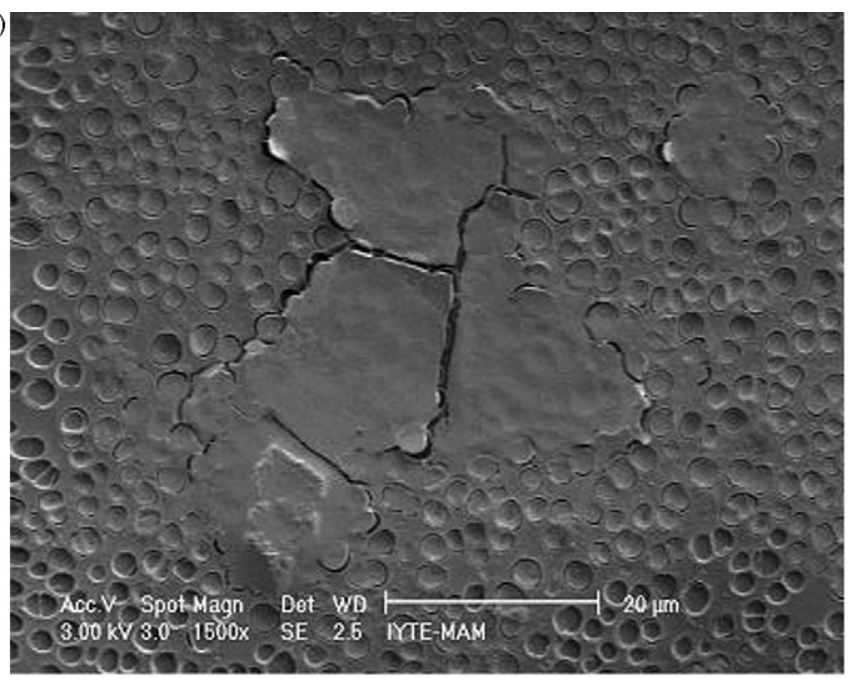

(c)

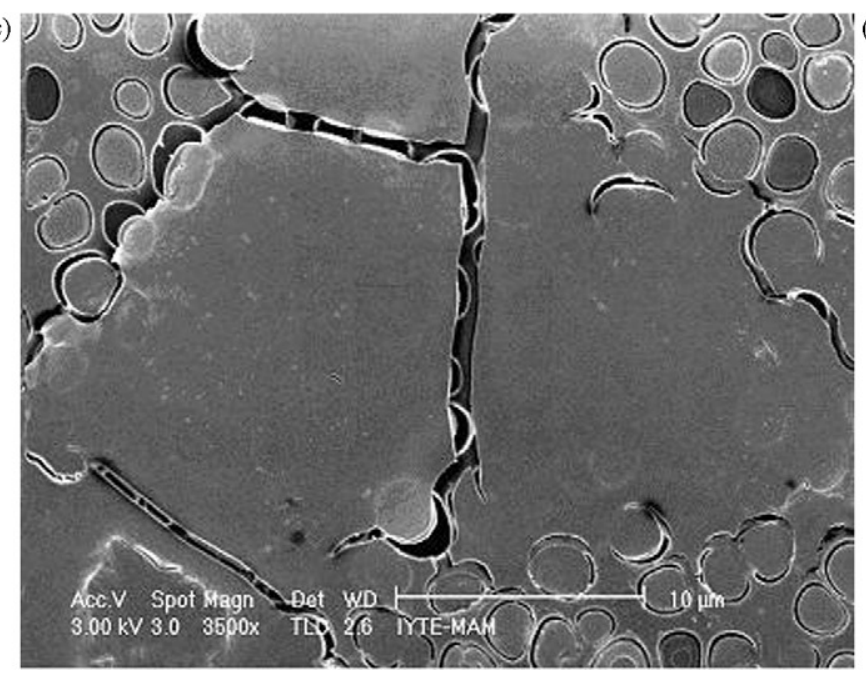

(b)
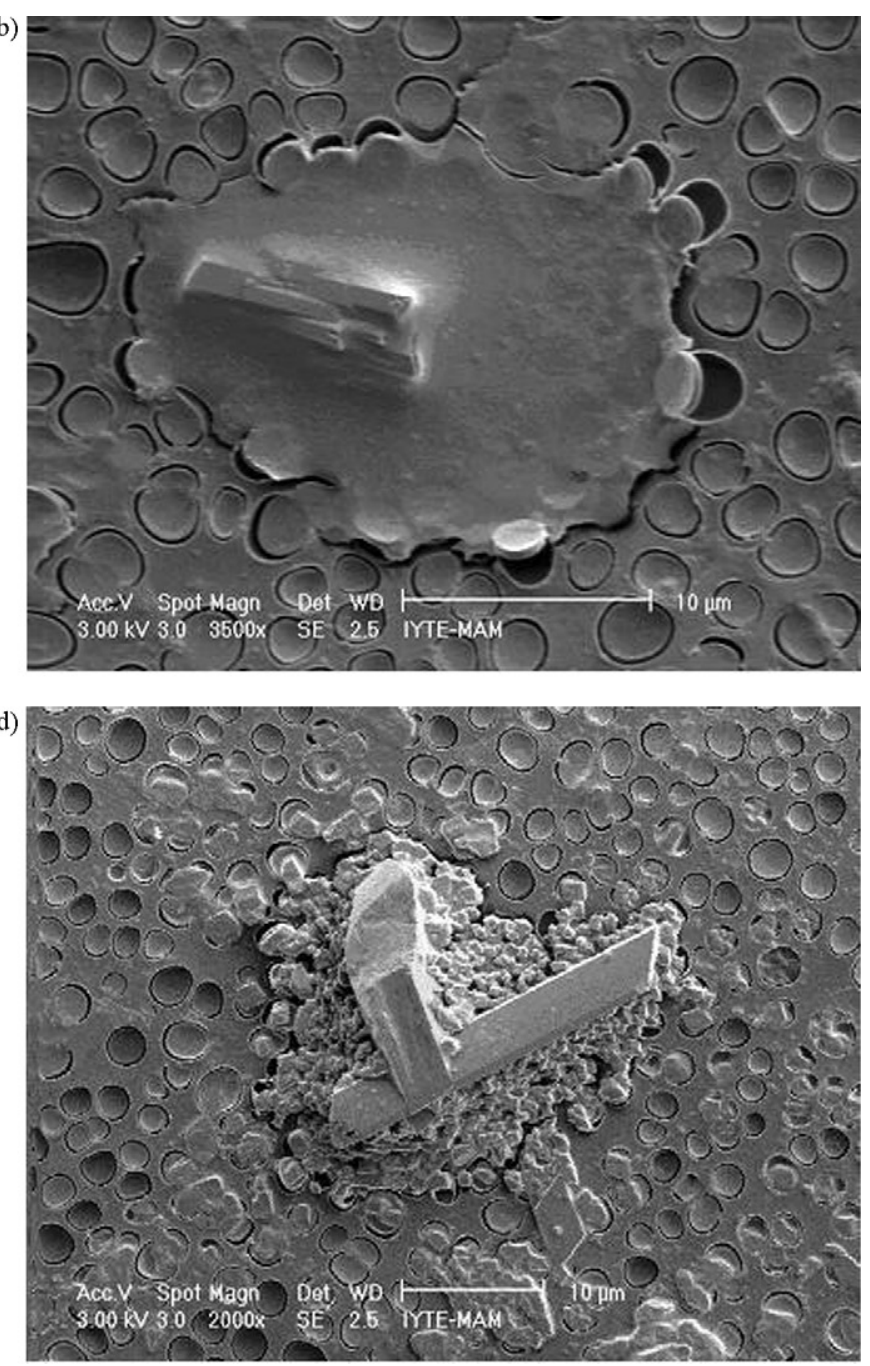

Fig. 13. Detailed SEM views of the cracks and tears $(\mathrm{a}-\mathrm{c})$ and gypsum crystals (d) formed on the HMWPLA coated surfaces after 90 days $\mathrm{SO}_{2}$. 


\section{Conclusions}

Biodegradable polymers are reversible, degradable, and allow new treatment of the material to be protected hence fulfil the principles generally accepted by the International Conservation Community of Historic Monuments and Buildings. In this study, protection performances of some biodegradable polymers on marble surfaces under the effect of $\mathrm{SO}_{2}$ gas have been investigated in the laboratory conditions. The tested biodegradable polymers were zein, chitosan, polyhydroxybutyrate, and poly-Llactide. Zein and chitosan polymers enhanced the $\mathrm{SO}_{2}$-marble reaction. Although they have good gas barrier properties, the acceleration of $\mathrm{SO}_{2}$-marble reaction on marble surfaces can be explained by entrapping much water vapor by polymers compared with uncoated marbles. The use of HMWPLA polymers on marble surfaces provided significant protection up to $60 \%$. The comparison among the polymers showed that the surface hydrophobicity and water capillary absorption and the structure of the coated polymer, would be important factors affecting the protection efficiency. The combined effects of these factors indicated that HMWPLA polymer seems to be promising polymer as protective coating agent in reducing gypsum formation on marble surfaces in the polluted environment.

\section{Acknowledgements}

This work was supported by the research grants of 104M564 (TUBITAK). The authors thank the researchers of the Centre for Materials Research for SEM-EDX and Centre for Environmental Research and Development for IC analysis at the İzmir Institute of Technology.

\section{References}

[1] P. Elfving, I. Panas, O. Lindqvist, Model study of the first steps in the deterioration of calcareous Stone. I. Initial surface sulphite formation on calcite, Appl. Surf. Sci. 74 (1994) 91-98.

[2] H. Böke, H. Göktürk, E. Caner-Saltık, N.Ş. Demirci, Effect of airborne particles on $\mathrm{SO}_{2}$-calcite reaction, Appl. Surf. Sci. 140 (1999) 70-82.

[3] K.L. Gauri, J.K. Bandyopadhyay, Carbonate Stone: Chemical Behavior, Durability and Conservation, Wiley-Interscience, New York, 1999.

[4] M. Thompson, J. Shelley, R.G. Compton, H.A. Viles, Polymer coatings to passivate calcite from acid attack: polyacrylic acid and polyacrylonitrile, J. Colloid Interface Sci. 260 (2003) 204-210.

[5] P. Elfving, L. Johannson, G. Lindquist, A study of the sulphation of silane-treated sandstone, Stud. Conserv. 39 (3) (1994) 199-209.
[6] K.L. Gauri, G.C. Doderer, N.T. Limscomp, A.C. Sarma, Reactivity of treated and untreated marble specimens in an $\mathrm{SO}_{2}$ atmosphere, Stud. Conserv. 18 (1973) 25-35.

[7] A. Tsakalof, P. Manoudis, I. Karapanagotis, I. Chryssoulakis, C. Panayiotou, Assessment of synthetic polymeric coatings for the protection and preservation of stone monuments, J. Cult. Herit. 8 (2007) 69-72.

[8] M. Zielecka, E. Bujnowska, Silicone containing polymer matrices as protective coatings: properties and applications, Prog. Org. Coat. 55 (2006) 160167.

[9] L. Toniolo, T. Poli, V. Castelvetro, A. Manariti, O. Chiantore, M. Lazzari, Tailoring new fluorinated acrylic copolymers as protective coatings for marble, J. Cult. Herit. 3 (2002) 309-316.

[10] P. Manoudis, S. Papadopoulou, I. Karapanagiotis, A. Tsakalof, I. Zuburtikudis, C. Panayiotou, Polymer silica nanoparticles composite films as protective coatings for stone-based monuments, J. Phys.: Conf. Ser. 6 (2007) 1361-1365.

[11] T.N. Skoulikidis, N. Beloyannis, Inversion of marble sulfation-reconversion of gypsum films into calcite on the surfaces of monuments and statues, Stud. Conserv. 29 (1984) 1733-1743.

[12] H. Böke, H. Göktürk, E.N. Caner-Saltık, Effect of some surfactants on $\mathrm{SO}_{2}$-marble reaction, Mater. Lett. 57 (2002) 935-939.

[13] H. Böke, K.L. Gauri, Reducing marble- $\mathrm{SO}_{2}$ reaction rate by the application of certain surfactants", Water Air Soil Pollut. 142 (2003) 59-70.

[14] M. Thompson, S.J. Wilkins, R.G. Compton, H.A. Viles, Channel flow cell studies on the evaluation of surface pre treatments using phosphoric acid or polymaleic acid for calcite stone protection, J. Colloid Interface Sci. 259 (2003) 338-345.

[15] E. Chiellini, R. Salero, Biodegradable Polymers and Plastics, Kluwer Academics, 2003.

[16] E.M.T. Shukla, M. Cheryan, Zein: the industrial protein from corn, Ind. Crops Prod. 13 (2001) 171-192.

[17] R.N. Tharanathan, Biodegradable films and composite coating: past, present and future, Trends Food Sci. Technol. 14 (2003) 71-78.

[18] P.C. Srinivas, R.N. Tharanathan, Chitin/chitosan-safe ecofriendly packaging material with multiple potential uses, Food Rev. Int. 23 (2007) 53-72.

[19] C.J. Weber, Biobased packaging materials for the food industry: status and perspectives, KVL (2000) 15-69.

[20] R. Auras, B. Harte, S. Selke, An overview of polylactides as packaging materials Macromol. Biosci. 4 (2004) 835-864.

[21] RILEM. Test defining the structure (1980) 13-13.

[22] P. Manoudis, A. Tsakalof, I. Karapanagiotis, I. Zuburtikudis, C. Panayiotou, Fabrication of super-hydrophobic surfaces for enhanced stone protection, Surf. Coat. Technol. 203 (2009) 1322-1328.

[23] M.C. Michalski, S. Desobry, J. Hardy, Food materials adhesion: a review, Crit. Rev. Food Sci. Nutr. 37 (1997) 591-619.

[24] M. Ballester, R. Gonzalez, Basic methodology for the assessment and selection of water repellent coating materials for stone, Prog. Org. Coat 43 (2001) 258-266.

[25] B. Sundqvist, T. Morǐen, The influence of wood polymers and extractives on wood colour induced by hydrothermal treatment, Holz als Roh- und Werkstoff 60 (2002) 375-376.

[26] R.J. Ashley, Permeability and plastic packaging, in: J. Comyn (Ed.), Polymer Permeability, Elsevier Applied Science, London, UK, 1985, pp. 269-308.

[27] H.M. Lai, G.W. Padua, Properties and microstructure of plasticized zein films, Cereal Chem. 74 (1997) 771-775.

[28] S. Despond, E. Espuche, A. Domard, Water sorption and permeation in chitosan films: relation between gas permeability and relative humidity, J. Polym. Sci. Part B: Polym. Phys. 39 (2001) 3114-3127. 